\title{
Association between tobacco prices and smoking onset: evidence from the TCP India Survey
}

\author{
Ce Shang, Frank J Chaloupka, ${ }^{1,2}$ Prakash C Gupta, ${ }^{3}$ Mangesh S Pednekar, ${ }^{3}$ \\ Geoffrey T Fong ${ }^{4,5}$
}

- Additional material is published online only. To view please visit the journal online (http://dx.doi.org/10.1136/ tobaccocontrol-2017-054178).

${ }^{1}$ Institute for Health Research and Policy, University of Illinois at Chicago, Chicago, Illinois, USA

${ }^{2}$ Department of Economics, University of Illinois at Chicago,

Chicago, Illinois, USA

${ }^{3}$ Healis Sekhsaria Institute for Public Health, Mumbai, Maharashtra, India

${ }^{4}$ Department of Psychology, University of Waterloo, Toronto, Ontario, Canada

${ }^{5}$ Ontario Institute for Cancer Research, Toronto, Ontario Canada

\section{Correspondence to}

Dr Ce Shang, OklahomaTobacco Research Center

StephensonCancer Center Departmentof Pediatrics University of Oklahoma HealthSciences Center 655Research Parkway, Suite 400 ; ce-shang@ouhsc.edu

Received 4 December 2017 Revised 5 September 2018 Accepted 7 September 2018 Published Online First 1 October 2018

\begin{abstract}
Background Tobacco use is prevalent among youth and adults in India. However, direct evidence on how increasing taxes or prices affect tobacco use onset is scarce.
\end{abstract}

Objective To analyse the associations between cigarette and bidi prices and smoking onset in India, and how these associations differ by socioeconomic status.

Methodology The Wave 1 of the Tobacco Control Policy Evaluation India Survey by the International Tobacco Control Project contains information on the age at smoking onset for cigarettes and bidis. Using this information, data were expanded to a yearly pseudo-panel dataset that tracked respondents at risk of smoking onset from 1998 to 2011. The associations between bidi prices and bidi smoking onset, between cigarette prices and cigarette smoking onset, and between bidi and cigarette prices and any smoking onset were examined using a discrete-time hazard model with a logit link function. Stratified analyses were conducted to examine the difference in these associations by rural versus urban division.

Results We found that higher bidi prices were significantly associated with a lowered hazard of bidi smoking onset (OR $0.42,95 \% \mathrm{Cl} 0.35$ to 0.51$)$. Higher cigarette prices were significantly $(\mathrm{OR} 0.87,95 \% \mathrm{Cl}$ 0.83 to 0.92 ) associated with a lowered hazard of cigarette smoking onset among urban residents, but this association was non-significant when SEs were clustered at the state level. In addition, the association between increasing bidis prices and lowered hazards of bidi smoking onset was greater for urban residents than for rural ones $(p<0.01)$.

Conclusions Under the new regime of a central goods and service system, policymakers may need to raise the prices of tobacco products sufficiently to curb smoking onset.

\section{INTRODUCTION}

India has one of the largest number of tobacco users in the world. ${ }^{12}$ In 2009-2010, 24.3\% of male adults and $2.9 \%$ of female adults in India were current tobacco users. Tobacco use is also prevalent among youth. The 2009 Global Youth Tobacco Survey in India shows that $19 \%$ of boys and $8.3 \%$ of girls were currently using some tobacco product. ${ }^{3}$ Additionally, $15.5 \%$ of youth never-smokers were likely to initiate smoking within the next year, showing the harmful impacts that tobacco poses to the population health in India. ${ }^{3}$

Since tobacco use is addictive, preventing never users from initiating tobacco use is a key area for tobacco control. As a signing Party of the WHO Framework Convention on Tobacco Control, ${ }^{4-6}$ India is in the progress of implementing a comprehensive set of tobacco control policies, many of which have been shown to reduce tobacco use onset. ${ }^{7}$ In particular, increasing taxes or prices is the most effective strategy in reducing tobacco use. ${ }^{910}$ A growing number of studies have shown that this strategy in general reduces demand for tobacco products in India, ${ }^{11-15}$ suggesting that increasing cost may reduce tobacco use onset. However, direct evidence on how increasing taxes or prices affect tobacco use onset is scarce.

Furthermore, several tobacco products, including cigarettes, bidis and smokeless tobacco, are popular in India. ${ }^{16}$ Due to their low cost, bidis and smokeless tobacco are more commonly used by lower-income tobacco users. ${ }^{17}$ As Indian consumers' income grows, cigarettes have been gradually displacing bidis. ${ }^{18}{ }^{19}$ Although most existing studies find prices of at least one product negatively associated with demand, ${ }^{11-15}$ how the price effects differ by products or different tobacco use margins (ie, smoking onset and cessation) is unclear. ${ }^{20} 21$ Evidence on the relationships among these products (ie, whether they are substitutes or complementarities) is also mixed and indicates that such relationships may vary by socioeconomic status. ${ }^{131422}$

To our knowledge, only one study evaluated the price effect on smoking onset in India. Using Global Adult Tobacco Survey data from 14 primarily low-income and middle- income countries, Kostova et al . showed that increasing prices reduced smoking onset in low-income to lower-middle-income countries but not in uppermiddle income countries. ${ }^{23}$ However, that study was conducted in a cross-country context, and India was used as one of many countries to derive the price elasticity of smoking onset for low-income and middle-income countries. There is lack of evidence on the tax or price effects on tobacco use onset specific to India.

This study aimed to fill this research gap by examining the associations between tobacco prices and smoking onset in four Indian states, which will in turn inform tax policies in the newly established central goods and service (GST) system. ${ }^{12}$ Capitalising on the self-reported retrospective information about the age at smoking onset, we constructed yearly pseudo panel datasets and examined the associations between prices and the hazards of smoking onset using a discrete-time hazard model. We also stratified the analyses by rural versus urban 
region to examine the difference in these associations by socioeconomic status.

\section{DATA AND MEASURES}

\section{Tobacco Control Policy (TCP) India Survey}

Tobacco Control Policy India Survey (TCP India) was conducted by the International Tobacco Control (ITC) Policy Evaluation Project the IT and the Healis-Sekhsaria Institute for Public Health, as part of the ITC parallel surveys in many countries. ${ }^{21} 24$ It is a prospective cohort survey of adults aged 15 years or older, including 8051 tobacco users (1255 smoked tobacco users, 5991 smokeless tobacco users and 805 mixed users) and 2534 non-users, in four Indian states: Maharashtra, Madhya Pradesh, Bihar, and West Bengal. ${ }^{24}$ In each state, respondents came from urban cities and their surrounding rural districts (Patna in Bihar, Kolkata in West Bengal, Indore in Madhya Pradesh and Mumbai in Maharashtra). The first wave was conducted between August 2010 and October 2011, and was used for the analyses.

\section{Age at smoking onset in TCP India data}

Among current tobacco users, TCP India Survey asked ever smokers of bidis and cigarettes to report their smoking onset using the following questions: 'At what age did you start smoking cigarettes?', and 'At what age did you start smoking bidis?'. Using the above self-reported retrospective information, we were able to identify the ages of cigarette and bidi smoking initiation, as well as the age when any form of smoking initiated (i.e., the initiation of either bidi or cigarette smoking). Specifically, for smokers who had smoked both bidis and cigarettes, we compared their age at bidi smoking onset with the age at cigarette smoking onset and used the younger onset age to identify any smoking initiation. Among smokers who had smoked both bidis and cigarettes, 62\% (309 out of 502 smokers) reported to initiate bidi and cigarette smoking at the same age.

Among non-users of tobacco, some had used tobacco products before. However, TCP India Survey did not ask them about their age of onset. As a result, we dropped 114 non-users who had smoked in the past but were abstinent at the time of the survey. The self-reported onset age of cigarette and bidi smoking are plotted in figure 1A,B. For both products, most frequently reported onset ages were $15,18,20$, and 25 .

\section{Tobacco prices}

Price data for bidis and cigarettes were collected monthly by experts in major cities of 24 states, including the four Indian states in the TCP India Survey, as part of routine large-scale price surveys used to construct consumer price indices (CPI) during the period 1998-2011. The collected prices were standardised to prices per 25 bidi sticks and prices per 10 cigarette sticks. Chewing tobacco prices were also collected for some of the states during a shorter period. Due to the missing data issue, we did not use chewing tobacco prices to examine smokeless tobacco onset in the analyses. Cigarette and bidi prices from 1998 to 2011 were used in the analyses. Given that TCP India Survey primarily surveyed respondents in Patna (Bihar), Kolkata (West Bengal), Indore (Madhya Pradesh) and Mumbai (Maharashtra), and their surrounding rural districts. We merged price data collected from Kolkata, Indore and Mumbai to the TCP India Survey using state identifiers. Unfortunately, tobacco prices from Patna were not available. Therefore, we merged the average tobacco prices of the Bihar state with respondents from that state in the TCP India data. Finally, these prices were adjusted for inflation and converted to 2010 rupees using the Indian national CPI reported in the World Development Indicator database.

\section{METHOD}

\section{Pseudo panel construction}

Following previous studies, ${ }^{23}$ we expanded the TCP India Survey to annual pseudo panel data by generating data entries for each year or age when respondents were at risk of onset but had not yet initiated. First, we assumed that everyone became at risk of smoking onset at age five. This cut-off was selected by examining the age at onset reported in the TCP India data, the age range of the survey ( 15 or above) and the availability of price data (1998-2011). In other words, age five is the baseline for the subsequent annual follow-ups and smoking onset would be observed since age six and onwards. Next, the onset outcome variable was a dummy, that is ' 0 ', when a respondent in that year or at that age had not become a smoker. Once a respondent started to smoke (i.e., reached the age that they reported in the survey to start smoking), the dummy was assigned with a ' 1 '. After a respondent became a smoker, the subsequent years were dropped from the sample. Therefore, for each respondent who eventually became a smoker, we observed the value ' 1 ' only once, which indicates the onset. For never-smokers including never tobacco users and smokeless tobacco users who never smoked, the outcome dummy is always ' 0 '. Such format is suitable for a survival analysis or a discrete-time hazard model that measures the probability of a change or a transition, such as smoking onset. $^{232829}$
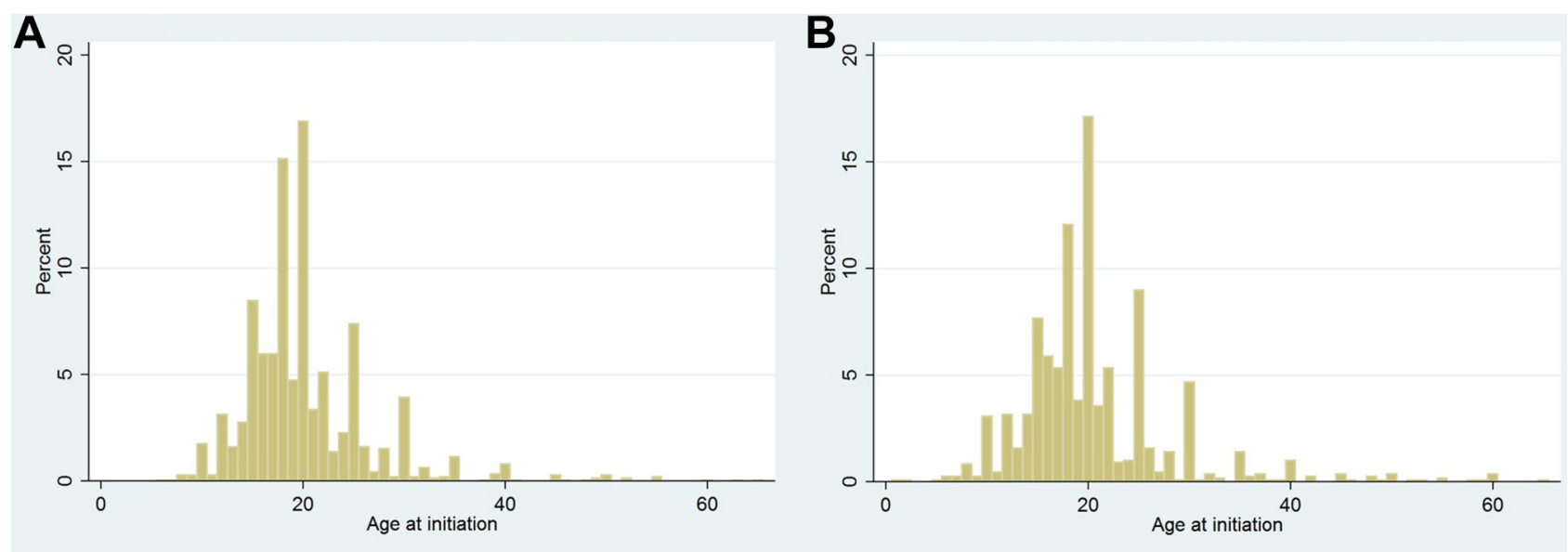

Figure 1 (A) Age at cigratte smoking onset. (B) Age at bidi smoking onset. 
The annual pseudo panel dataset was constructed separately for cigarette smoking onset, bidi smoking onset and any smoking onset. In the dataset used for estimating cigarette smoking onset, 0 implies that the respondent had not initiated cigarette smoking that year, whereas 1 implies that the respondent initiated cigarette smoking that year. Similarly, in the dataset used for estimating bidi smoking onset, 0 implies that the respondent had not initiated bidi smoking that year, whereas 1 implies that the respondent initiated bidi smoking that year. Finally, in the dataset used for estimating any smoking onset, 0 implies that the respondent had not initiated bidi or cigarette smoking (the respondent was a never-smoker) that year, whereas 1 implies that the respondent initiated smoking bidis or cigarettes or both that year.

\section{Data merging and discrete-time hazard model}

To conduct the analyses, we merged the annual pseudo panel datasets with cigarette and bidi prices using year and state identifiers. The final analytical datasets span from 1998 to 2011. The associations between tobacco prices and smoking onset were then estimated using weighted logistic regressions, which have been commonly used in the literature to estimate a discrete-time hazard model. ${ }^{27}{ }^{30}$ Specifically, we regressed cigarette onset on cigarette prices, bidi onset on bidi prices and any smoking onset on both cigarette and bidi prices. In the regression analyses, we controlled for a linear year trend, state fixed effects, timevarying age dummies, age squared, gender, and urban residency at the time of survey (Model 1). We also controlled for duration dependency, which is a log form of years since age five. ${ }^{29}$ Duration dependency controls for the hazards of outcomes change over time (ie, how likely smoking onset would occur overt time). ${ }^{28}$ Analyses were also evaluated by replacing the linear year trend with year fixed effects (Model 2), which is a difference-in-difference approach. We conducted both Models 1 and 2 because cigarette and bidi prices were highly correlated with state and year fixed effects in the study period-they together explained $97 \%$ of variation in cigarette prices and $96 \%$ in bidi prices. Nonetheless, Model 2 was taken as the benchmark model throughout this study.

We further analysed the benchmark model using subsamples stratified by urban versus rural residency at the time of the TCP India Survey and tested the difference in the associations between prices and smoking onset by residency. By doing so, we made the assumption that respondents did not move between urban and rural areas over time. Additional analyses stratified by gender were also conducted and results are available on request. We conducted two sets of sensitivity analyses using the benchmark model. The first set used age six instead of age five as the youngest age to be at risk of smoking onset. The second set used only price data from 2003 to 2011 because some Indian states may have changed their data collection method around 2002, although this change did not seem to happen in the four Indian states in the TCP India Survey. All regressions accounted for inter-temporal correlations within the same individual and were conducted using Stata V.14.1.

\section{FINDINGS}

In table 1, we report summary statistics for the samples used to analyse cigarette smoking onset $(n=111996)$, bidi smoking onset $(n=113566)$ and any smoking onset $(n=105402)$, and for samples stratified by rural/urban division. The average probabilities of initiating smoking were $6.2 \%-6.3 \%$. The means of other independent variables were roughly the same across the

\begin{tabular}{llll}
\hline \multicolumn{1}{l}{ Table 1} & Weighted summary statistics & \\
\hline Variable/mean (SD) & Full sample & Urban & Rural \\
\hline Cigarette onset sample & $(\mathrm{n}=111996)$ & $(\mathrm{n}=81387)$ & $(\mathrm{n}=30609)$ \\
\hline Cigarette onset & $0.063(0.243)$ & $0.062(0.242)$ & $0.064(0.245)$ \\
Male & $0.561(0.496)$ & $0.559(0.497)$ & $0.565(0.496)$ \\
Rural & $0.272(0.445)$ & - & - \\
Duration dependency & $3.181(0.722)$ & $3.188(0.718)$ & $3.166(0.732)$ \\
Time-varying age & $34.587(16.644)$ & $34.692(16.61)$ & $34.305(16.73)$ \\
Cigarette prices & $18.601(3.959)$ & $18.562(3.932)$ & $18.705(4.027)$ \\
Bidi onset sample & $(\mathrm{n}=113566)$ & $(\mathrm{n}=84576)$ & $(\mathrm{n}=28990)$ \\
\hline Bidi onset & $0.062(0.242)$ & $0.062(0.241)$ & $0.063(0.243)$ \\
Male & $0.569(0.495)$ & $0.578(0.494)$ & $0.544(0.498)$ \\
Rural & $0.254(0.435)$ & - & - \\
Duration dependency & $3.169(0.715)$ & $3.181(0.707)$ & $3.134(0.739)$ \\
Time-varying age & $34.159(16.421)$ & $34.375(16.342)$ & $33.526(16.636)$ \\
\hline Bidi prices & $6.018(1.261)$ & $6(1.248)$ & $6.069(1.297)$ \\
Smoking onset & $(\mathrm{n}=105402)$ & $(\mathrm{n}=77584)$ & $(\mathrm{n}=27818)$ \\
Smoking onset & $0.063(0.241)$ & $0.062(0.241)$ & $0.063(0.243)$ \\
Male & $0.536(0.499)$ & $0.54(0.498)$ & $0.524(0.499)$ \\
Rural & $0.262(0.44)$ & - & - \\
Duration dependency & $3.155(0.73)$ & $3.165(0.724)$ & $3.127(0.747)$ \\
Time-varying age & $34(16.659)$ & $34.181(16.595)$ & $33.486(16.828)$ \\
Bidi prices & $6.037(1.268)$ & $6.019(1.257)$ & $6.086(1.297)$ \\
Cigarette prices & $18.582(3.957)$ & $18.55(3.93)$ & $18.67(4.03)$ \\
\hline
\end{tabular}

three samples. The percentage of males ranged from $54 \%$ to $57 \%$, and the percentage of respondents living in rural areas was 26\%-27\%. The duration dependency measured using the log form of years since age five was around 3.2. The average age was $35-36$ years. Bidi prices per 25 sticks were around 6 rupees, and cigarette prices per 10 sticks were around 19 rupees. In addition, smoking onset probabilities were almost identical across urban and rural regions.

Table 2 contains results from estimating the associations between tobacco prices and smoking onset using two alternative models. Time trend was controlled for using a linear year trend in the first model, and using year fixed effects in the second model. When a linear year trend instead of year fixed effects was controlled for, higher cigarette prices were significantly associated with a lowered hazard of cigarette smoking onset (Model 1, column 1: OR $0.87,95 \%$ CI 0.83 to 0.92 ). However, this association became non-significant once the linear trend was replaced by year fixed effects as control variables. In addition, higher bidi prices were significantly associated with a lowered hazard of bidi smoking onset (Model 2, column 4: OR 0.42, 95\% CI 0.35 to 0.51 ), and with a lowered hazard of any smoking onset (Model 2, column 6: OR 0.67, 95\% CI 0.56 to 0.81 ) prices were associated with a lowered hazard of any smoking initiation. Interestingly, Model 1 (column 5) suggests that higher cigarette prices were associated with a lowered hazard of any smoking onset. However, once year fixed effects were controlled for (Model 2, column 6), the association between cigarette prices and any smoking onset turned positive.

Table 3 contains results from stratified regressions by rural versus urban region, which show distinctive patterns for the association between cigarette prices and smoking onset by the stratification. Specifically, for respondents who lived in urban areas at the time of survey, higher cigarette prices were significantly (column 1: OR $0.91,95 \%$ CI 0.86 to 0.97 ) associated with a lowered hazard of cigarette smoking onset. In contrast, for respondents who lived in a rural area at the time of survey, 
Table 2 The associations between tobacco prices and smoking onset

\begin{tabular}{|c|c|c|c|c|c|c|}
\hline \multirow[b]{2}{*}{ Variable } & \multicolumn{2}{|c|}{ Cigarette smoking onset ( $n=111996)$} & \multicolumn{2}{|c|}{ Bidi smoking onset $(n=113566)$} & \multicolumn{2}{|c|}{ Any smoking onset $(n=105402)$} \\
\hline & (1) & (2) & (3) & (4) & $(5)$ & (6) \\
\hline $\begin{array}{l}\text { Cigarette prices } \\
(\mathrm{OR}, 95 \% \mathrm{Cl})\end{array}$ & $\begin{array}{l}0.87^{* *} \\
\text { (0.83 to } 0.92 \text { ) }\end{array}$ & $\begin{array}{l}1.03 \\
\text { (0.98 to } 1.08)\end{array}$ & - & - & $\begin{array}{l}0.87^{* *} \\
(0.83 \text { to } 0.9)\end{array}$ & $\begin{array}{l}1.08^{* *} \\
\text { (1.03 to } 1.13)\end{array}$ \\
\hline $\begin{array}{l}\text { Bidi prices } \\
(\mathrm{OR}, 95 \% \mathrm{Cl})\end{array}$ & - & - & $-\dagger$ & $\begin{array}{l}0.42^{* *} \\
(0.35 \text { to } 0.51)\end{array}$ & $\begin{array}{l}0.84^{*} \\
\text { (0.70 to } 1.02)\end{array}$ & $\begin{array}{l}0.67^{* *} \\
(0.56 \text { to } 0.81)\end{array}$ \\
\hline Model 1: linear year trend & Yes & No & Yes & No & Yes & No \\
\hline Model 2: year effects & No & Yes & No & Yes & No & Yes \\
\hline
\end{tabular}

Weighted logistic regressions also controlled for duration dependency, time-varying age, age squared, gender, a dummy of residing in rural areas at the time of survey and state fixed effects. SEs were clustered to adjust for inter-temporal correlations within the same individual. Elasticity estimates for significant negative associations between cigarette prices and smoking onset are -2.4 (column 1 ) and -2.5 (column 5). Elasticity estimates for significant associations between bidi prices and smoking onset are -4.8 (column 4 ), -1.0 (column 5) and -2.2 (column 6).

${ }^{*} \mathrm{p}<0.1,{ }^{* *} \mathrm{p}<0.01$.

tThe logit regressions with a linear year trend did not converge.

higher cigarette prices were associated with an increased hazard of cigarette smoking onset (column 2: OR 1.35, 95\% CI 1.19 to 1.53 ). For both urban and rural residents, higher bidi prices were associated with a lowered hazard of bidi smoking onset (column 3, urban: OR $0.27,95 \%$ CI 0.22 to 0.34 ; column 4, rural: OR $0.64,95 \% \mathrm{CI} 0.41$ to 1.00 ). Furthermore, cigarette prices were not significantly associated with any smoking onset in urban areas and positively associated with any smoking onset in rural areas (column 6: PR 1.34, 95\% CI 1.2 to 1.5). Bidi prices were significantly associated with lowered hazards of smoking onset in both areas (column 5, urban: OR 0.54, 95\% CI 0.43 to 0.68 ; column 6 , rural: OR $0.69,95 \%$ CI 0.46 to 1.02 ). Wald tests suggest that, for both urban and rural residents (table 3, columns 5 and 6), the association between bidi prices and any smoking onset significantly differs from that between cigarette prices and any smoking onset $(p<0.01)$. Chow test results indicate that the associations between cigarette prices and smoking onset (cigarette smoking onset and any smoking onset) significantly differ by rural/urban division $(\mathrm{p}<0.01)$. In addition, the association between increasing bidis prices and lowered hazards of bidi smoking onset was greater for urban residents than for rural ones $(p<0.01)$. Sensitivity analyses using an age six cut-off as the baseline for being at risk of smoking onset and using the price data from 2003 to 2011 both showed very similar results.

\section{DISCUSSION}

We estimated that higher bidi prices were significantly associated with lowered hazards of bidi smoking onset and smoking onset in general. Further, for urban residents in the four Indian states, higher cigarette prices were significantly associated with a lowered hazard of cigarette smoking onset. These findings add to the evidence that increasing taxes and prices of tobacco products may reduce tobacco use onset in India. Kostova et al. suggest that increasing tobacco prices likely reduces smoking through reducing smoking onset in low-income to lower-income countries, including India, and through promoting quitting in upper middle-income countries. ${ }^{30}$ Combined with evidence that prices were not significantly associated with quitting in India, ${ }^{20}$ this study provides additional support to the mechanism discussed in Kostova et al. with regards to the differential impacts of increasing prices on smoking dynamics by countries' income levels.

Our results also suggest that, for urban residents at the time of survey, the negative association between bidi prices and bidi smoking onset appeared more pronounced than the association between cigarette prices and cigarette smoking onset. These findings indicate that bidi prices may have a greater impact on reducing smoking onset than cigarette prices. However, this pattern needs to be explained in the context of existing literature on the comparison between cigarette and bidi prices with regards to their effects in reducing smoking. Some earlier studies found that the effects of bidi prices on smoking appear to be greater than the effects of cigarette prices. ${ }^{11}{ }^{14}$ However, studies using more recent data suggest that cigarette taxes have a greater impact on reducing smoking and that cigarettes have been displacing bidis in recent years. ${ }^{1518} 19$ Given that we used historical price data from 1998 to 2011 linked with retrospective information on smoking initiation, it is not surprising that the associations between bidi prices and smoking onset were found to be greater than the associations between cigarette prices and smoking onset. In addition, because bidi prices have been much cheaper than cigarette prices, they may play a bigger role in smoking onset.

Table 3 The associations between tobacco prices and smoking onset, by urban versus rural division

\begin{tabular}{|c|c|c|c|c|c|c|}
\hline \multirow[b]{2}{*}{ Variable } & \multicolumn{2}{|c|}{ Cigarette smoking onset } & \multicolumn{2}{|c|}{ Bidi smoking onset } & \multicolumn{2}{|c|}{ Any smoking onset } \\
\hline & (1) & (2) & (3) & (4) & (5) & (6) \\
\hline Residence at the time of survey & Urban $(n=81387)$ & $\begin{array}{l}\text { Rural } \\
(n=30609)\end{array}$ & $\begin{array}{l}\text { Urban } \\
(\mathrm{n}=84576)\end{array}$ & $\begin{array}{l}\text { Rural } \\
(n=28990)\end{array}$ & $\begin{array}{l}\text { Urban } \\
(\mathrm{n}=77584)\end{array}$ & $\begin{array}{l}\text { Rural } \\
(n=27818)\end{array}$ \\
\hline Cigarette prices (OR, 95\% Cl) & $\begin{array}{l}0.91^{* *} \\
(0.86 \text { to } 0.97)\end{array}$ & $\begin{array}{l}1.35^{* *} \\
\text { (1.19 to } 1.53)\end{array}$ & - & - & $\begin{array}{l}0.98 \\
(0.92 \text { to } 1.03)\end{array}$ & $\begin{array}{l}1.34^{* *} \\
(1.2 \text { to } 1.5)\end{array}$ \\
\hline Bidi prices (OR, 95\% Cl) & - & - & $\begin{array}{l}0.27^{* *} \\
(0.22 \text { to } 0.34)\end{array}$ & $\begin{array}{l}0.64^{*} \\
(0.41 \text { to } 1.01)\end{array}$ & $\begin{array}{l}0.54^{* *} \\
(0.43 \text { to } 0.68)\end{array}$ & $\begin{array}{l}0.69^{*} \\
(0.46 \text { to } 1.02)\end{array}$ \\
\hline
\end{tabular}

Weighted logistic regressions also controlled for time-varying age, age squared, gender, year fixed effects, and state fixed effects. SEs were clustered to adjust for inter-temporal correlations within the same individual. Elasticity estimate for the significant negative association between cigarette prices and smoking onset is -1.5 (column 1 ). Elasticity estimates for significant negative associations between bidi prices and smoking onset are -7.3 (column 3), -2.5 (column 4), 3.5 (column 5 ) and -2.1 (column 6). ${ }^{*} p<0.1,{ }^{* *} p<0.01$ 
Previous studies also suggest that tobacco use and price effects in India may differ by socioeconomic status. ${ }^{12} 1318$ Selvaraj et al. found that the price effects on tobacco use were greater for poorer groups. ${ }^{12}$ Therefore, we conducted stratified analyses by rural versus urban division. Unlike previous studies, we found that the negative associations between higher tobacco prices and lowered hazards of smoking onset were greater among urban residents than among rural residents. In fact, for rural respondents at the time of survey, cigarette prices were positively associated with smoking onset.

There are several potential explanations. First, rural respondents in the TCP survey came from rural districts close to cities. With a growing economy, smokers may become more likely to initiate with cigarettes despite higher cigarette prices compared with bidi prices. There are studies documenting that cigarettes have been displacing bidis in recent years, which also support this hypothesis. ${ }^{18} 19$ Second, we could not observe migration between rural and urban divisions in the survey data and assumed that respondents never moved during the study period. This assumption may be violated and thus lead to biased estimates if people who smoked became poor and as a result moved from urban to poorer rural districts. Third, we used price data collected from major cities, which may differ from the prices in rural areas and lead to biased estimates.

Our results also add to the literature on the association between tobacco prices and smoking onset in low-income and middle-income countries. Three recent studies investigated the effects of increasing tobacco prices on smoking onset in South Africa, Argentina, and Vietnam, respectively. ${ }^{26} 2731$ Two of those studies used national-level prices over time in the analyses and could not control for the time trend of tobacco use behaviours and tobacco control actions. ${ }^{26} 31$ Nonetheless, they found that increasing prices significantly reduce smoking onset, with a price elasticity for onset hazards ranging from -0.4 to -0.9 . Unlike those studies, our study employed within-state price variation over time in India to evaluate the relationship between prices and smoking onset, and thus was able to tease out the common time trend and state-level time-invariant sentiment towards tobacco control and tobacco use. Our findings suggest greater price elasticity estimates for onset hazards, which centred on a range from -1.5 to -2.5 . The magnitude of these elasticity estimates are large but comparable to another study that also used local-level prices in Vietnam to identify the price impacts on smoking onset. ${ }^{27}$

This study does not identify the causal impact of prices on smoking onset because it lacks a clean source of quasi-experimental variation in bid prices. However, there is suggestive evidence that the results are not due to market-level simultaneity between demand and bidi prices. According to Jha et al. ${ }^{19}$ the bidi industry has a large number of small manufacturers and none of these manufacturers took more than $5 \%$ of the market share. To the extent the bidi market approximates a competitive market with constant marginal cost, bidi prices are not endogenous due to market-level simultaneity. Other sources of econometric endogeneity cannot be ruled out and might still lead to spurious associations between prices and smoking onset. The association between bidi prices was robust to clustering at the state level and the additional control of state-specific year trends (online supplementary appendix table). An important caveat is that the small number of states creates difficult challenges for statistical inference. ${ }^{32}$ Finally, although smokeless tobacco users were considered together with non-tobacco users in the analyses, the prices of smokeless tobacco may not bias the results because different tobacco products in India have distinct markets. ${ }^{13} 19$

Similar to many other studies, this study is subject to several limitations. First, the TCP India Survey did not contain information of smoking onset for respondents who were no longer smokers at the time of survey. Second, ages at smoking onset were self-reported and may contain recall errors. The reported onset ages also appear to be heaping at certain ages such as 10 , 15, 20 and 25. Third, the TCP India Survey is not nationally representative and we cannot infer the population-level effects of increasing prices on smoking onset. Because there were only four states in the survey, we could not adjust for inter-temporal correlations among respondents who lived in the same state. The results may be subject to omitted variable bias, such as timevarying tobacco control sentiment and preferences for tobacco. In addition, price data were collected from major cities and may not reflect tobacco prices in rural areas. Lastly, this study relies on several assumptions (e.g., respondents never moved between rural and urban areas) and violation of these assumptions may lead to biased estimates.

In sum, we found that increasing cigarette and bidi prices were significantly associated with lowered hazards of smoking onset in four Indian states, particularly among urban residents. Among rural residents who lived near cities in those states, increasing bidi prices were significantly associated with lowered hazards of smoking onset. However, we also found that cigarette prices were positively associated with the hazards of smoking onset among rural residents, which may be a result of cigarettes replacing bidis in the rural districts. Under the new regime of a central GST system, policymakers

\section{What this paper adds}

What is already known on this subject

- Increasing tobacco prices reduce tobacco demand in India.

- These price effects tend to differ by socioeconomic status.

What important gaps in knowledge exist on this topic

- To our knowledge, very few studies examined how bidi and cigarette prices were associated with smoking onset in India.

- There is lack of evidence on how price effects on smoking onset differ by products and by socioeconomic status.

What this paper adds

- Our study provides empirical evidence on the associations between cigarette and bidi prices and smoking onset in four Indian states, and how these effects differ by rural versus urban division.

- We found that increasing cigarette and bidi prices significantly reduced smoking onset among urban residents in four Indian states.

- Higher bidi prices were significantly associated with a lowered hazard of bidi smoking onset.

- Higher cigarette prices were significantly associated with a lowered hazard of cigarette smoking onset among urban residents.

- The association between increasing bidis prices and lowered hazards of bidi smoking onset was greater for urban residents than for rural ones.

- Under the new regime of a central goods and service system, policymakers may need to raise the prices of tobacco products at the lower-priced end such as bidis to curb smoking onset. 
may need to raise the prices of tobacco products sufficiently to curb smoking onset.

Correction notice This article has been corrected since it was published Online First. Additional details of funding have been added.

Contributors CS conducted the analyses and wrote the manuscript. All authors contributed to study design and reports interpretation. The findings and conclusions in this article are those of the authors.

Funding The TCP India Project was supported by grants from the U.S. National Cancer Institute (P50 CA111236, P01 CA138389) and Canadian Institute of Health Research (MOP-79551 and MOP-115016). Additional support was provided to Geoffrey T. Fong from a Senior Investigator Award from the Ontario Institute for Cancer Research and a Prevention Scientist Award from the Canadian Cancer Society Research Institute. Additional support in preparing this paper was provided to University of Waterloo by the Canadian Institutes of Health Research (FDN-148477).

Competing interests None declared.

Patient consent Obtained.

Ethics approval Ethics approval Office of Research Ethics, University of Waterloo, Canada and International Research Board, Healis Sekhsaria Institute for Public Health, India.

Provenance and peer review Not commissioned; externally peer reviewed.

\section{REFERENCES}

1 Jha P, Jacob B, Gajalakshmi V, et al. A nationally representative case-control study of smoking and death in India. N Eng/ J Med 2008;358:1137-47.

2 John RM, Sung HY, Max W. Economic cost of tobacco use in India, 2004. Tob Control 2009;18:138-43.

3 Vendhan G. India (Ages 13-15) Global Youth Tobacco Survey (GYTS) fact sheet.

4 Ngo A, Cheng KW, Chaloupka FJ, et al. The effect of MPOWER scores on cigarette smoking prevalence and consumption. Prev Med 2017;105S:S10-S14.

5 Organization WH. WHO report on the global tobacco epidemic 2013, 2013.

6 Organization WH. Parties to the WHO framework convention on tobacco control, 2017.

7 Organization WH. MPOWER: six policies to reverse the tobacco epidemic, 2008.

8 Organization WH. MPOWER in action: defeating the global tobacco epidemic, 2013.

9 Chaloupka FJ, Straif K, Leon ME. Working Group, International Agency for Research on Cancer. Effectiveness of tax and price policies in tobacco control. Tob Control 2011;20:235-8

10 Organization WH. WHO report on the global tobacco epidemic, 2015: raising taxes on tobacco, 2015.

11 Joseph RA, Chaloupka FJ. The influence of prices on youth tobacco use in India. Nicotine Tob Res 2014;16 Suppl 1:S24-S29.

12 Selvaraj S, Srivastava S, Karan A. Price elasticity of tobacco products among economic classes in India, 2011-2012. BMJ Open 2015;5:e008180.
13 Guindon GE, Nandi A, Chaloupka Iv FJ, et al. Socioeconomic differences in the impact of smoking tobacco and alcohol prices on smoking in India: National Bureau of Economic Research, 2011.

14 John RM. Price elasticity estimates for tobacco products in India. Health Policy Plan 2008:23:200-9.

15 Shang C, Chaloupka FJ, Fong GT, et al. The association between state value-added taxes and tobacco use in India- Evidence from GATS and TCP India survey. Nicotine Tob Res 2017.

16 International Institute for Population Sciences, 2010. Global adult tobacco survey, fact sheet India, 2009-2010. http://www.who.int/tobacco/surveillance/en_tfi_india_gats_ fact_sheet.pdf

17 Singh A, Arora M, English DR, et al. Socioeconomic gradients in different types of tobacco use in india: evidence from global adult tobacco survey 2009-10. Biomed Res Int 2015;2015:1-9.

18 Mishra S, Joseph RA, Gupta PC, et al. Trends in bidi and cigarette smoking in India from 1998 to 2015, by age, gender and education. BMJ Glob Health 2016;1:e000005.

19 Jha P, Guindon E, Joseph RA, et al. A rational taxation system of bidis and cigarettes to reduce smoking deaths in India. Econ Polit Wkly 2011:42:44-51.

20 Shang C, Chaloupka F, Kostova D. Who quits? An overview of quitters in low- and middle-income countries. Nicotine Tob Res 2014;16 Suppl 1:S44-S55.

21 Pawar PS, Pednekar MS, Gupta PC, et al. The relation between price and daily consumption of cigarettes and bidis: findings from the Tobacco Control Policy Evaluation Wave 1 Survey. Indian I Cancer 2014;51(Suppl 1):S83-7.

22 Kostova D, Dave D. Smokeless tobacco use in India: Role of prices and advertising. Soc Sci Med 2015;138:82-90.

23 Kostova D, Chaloupka FJ, Shang C. A duration analysis of the role of cigarette prices on smoking initiation and cessation in developing countries. Eur J Health Econ 2015; 16:279-88

24 Project I. TCP India National Report. Findings from the wave 1 survey (2010-2011). Waterloo, Ontario, Canada; Navi Mumbai, India: University of Waterloo, HealisSekhsaria Institute for Public Health, 2013.

25 Lillard DR, Molloy E, Sfekas A. Smoking initiation and the iron law of demand. J Health Econ 2013;32:114-27.

26 Guindon GE, Paraje GR, Chávez R. Prices, inflation, and smoking onset: the case of Argentina. Econ Inq 2018;56:424-45.

27 Guindon GE. The impact of tobacco prices on smoking onset in Vietnam: duration analyses of retrospective data. Eur J Health Econ 2014;15:19-39.

28 Guindon GE. The impact of tobacco prices on smoking onset: a methodological review. Tob Control 2014;23.

29 Shang $C$. The effect of smoke-free air law in bars on smoking initiation and relapse among teenagers and young adults. Int J Environ Res Public Health 2015;12:504-20.

30 Kostova D, Chaloupka FJ, Yurekli A, et al. A cross-country study of cigarette prices and affordability: evidence from the Global Adult Tobacco Survey. Tob Control 2014;23:e3.

31 Vellios N, van Walbeek C. Determinants of regular smoking onset in South Africa using duration analysis. BMJ Open 2016;6:e011076.

32 Colin Cameron A, Miller DL. A practitioner's guide to cluster-robust inference. J Hum Resour 2015:50:317-72. 